\title{
Práticas
}

\section{educomunicativas e a redução da violência no contexto escolar}

\author{
Marciel A. Consani \\ Docente e pesquisador do Departamento de Comunicações e Artes (CCA) da ECA-USP. \\ E-mail:mconsani@usp.br
}

Maria Carolina Aguilera Maccagnini

Especialista em Educomunicação pelo CCA-ECA-USP.

E-mail: carolina414@hotmail.com

Resumo: Este texto se propõe a abordar a questão das práticas educomunicativas como ações de mediação de conflitos baseadas na promoção do diálogo e na aproximação entre os diversos atores sociais presentes no processo educativo. Nosso recorte é o locus escolar, onde foi implementado o projeto Educom.Rádio, na medida em que o direcionamento efetivo da Educomunicação para o âmbito das políticas públicas, naquela ocasião (2001-2004), ocorreu pela demanda apresentada pela rede pública paulistana por alternativas inovadoras que promovessem a redução da violência nas escolas. Passada mais de uma década do encerramento daquele projeto, consideramos oportuno analisar a efetividade das ações dos educomunicadores na redução da violência escolar. Esta pode ser identificada, principalmente, com a melhoria das relações dialógicas interpessoais/intergrupos e com a promoção da Cultura da Paz.

Palavras-chave: educomunicação; dialogicidade; violência escolar; Cultura da Paz; escola pública.
Abstract: This paper proposes to address the issue of educommunicative practices such as actions of conflict mediation based on the promotion of dialogue and on rapprochement between various social actors present in the educational process. Our scope is the school locus, where the Educom.Rádio project was implemented, to the extent that the actual direction of Educommunication to public policy - at that time (2001-2004) - occured because São Paulo public shools needed innovative alternatives that could promote the reduction of violence in that context. After more than a decade of the end of that project, we consider appropriate to examine the effectiveness of the actions of educommunicators in reducing school violence. This can be identified mainly with the improvement of interpersonal and intergroups dialogical relationships and with the promotion of Culture of Peace.

Keywords: educommunication; dialogue; school violence; Cultura of Peace; public school. 
comunicação \& educação • Ano XX • número 2 • jul/dez 2015

\section{INTRODUÇÃO}

De estratégia educacional alternativa até sua inserção no âmbito das políticas públicas, a Educomunicação e suas práticas sempre foram relacionadas com a promoção do diálogo e outras ações visando o estabelecimento de um ecossistema comunicativo saudável e democrático.

Não é surpresa, portanto, que o projeto Educom.Rádio tenha sido implantado com base na premissa de que a Educomunicação poderia reduzir a violência (agressões e depredação) nas escolas públicas da Secretaria Municipal de Educação de São Paulo (SME-SP). Esta narrativa nos é dada, em primeira mão, pelo pesquisador Ismar Soares, numa entrevista concedida para apresentação no âmbito do I Congreso Internacional de Educacion Mediatica y Competencia Digital $^{1}$. Outro vídeo, este institucional ${ }^{2}$, apresenta a então secretária da SME-SP, Cida Peres, confirmando a percepção de que a implantação do projeto teria reduzido os casos de violência escolar em $50 \%$.

Tais afirmações reputaram a Educomunicação como um referencial eficaz

1 CONSANI, M. A.; LEÃO M. I. de A. Nas ondas do rádio: a experiência educomunicativa e midiática dos professores de São Paulo. Texto publicado nos Anais do I Congreso de Educacion Mediatica y Competencia Digital. Disponível em: <http:// educacionmediatica.es/ comunicaciones/Eje\%203/ Marciel\%20A.\%20Con sani\%20e\%20lzabel\%20 Le\%C3\%A3o.pdf>. Acesso em: 25 mar. 2015.

2 JIMENEZ, Márcia Coutinho R. Vídeo Institucional Projeto Educom.Rádio. 2011, cor, 18m19s, formato digital. Disponível em: <www.youtube.com/ watch?v=FDEVvZY164U>. Acesso em: 25 mar. 2015.

3 MACCAGNINI, Maria Carolina A. Educomunicação na escola: a violência urbana na cidade de São Paulo e o caso da EMEF Professora Marili Dias. Monografia do curso de Especialização em Educomunicação apresentada ao CCA-ECA-USP, São Paulo, 2015.

4 MARTÍN-BARBERO, J. A comunicação na educação. São Paulo: Contexto, 2014. e eficiente de conceitos e práticas no combate à violência escolar. Entretanto, devemos admitir que a escassez de dados acadêmicos ou mesmo de estudos sistematizados dificultam um embasamento consistente e inequívoco para tais posições.

Nesse sentido, enxergamos a necessidade de revisar e atualizar os aspectos envolvidos na mediação educomunicativa como uma ação contra violência escolar. A ideia nasceu como um desdobramento do trabalho apresentado pela coautora deste artigo $^{3}$ ao término de seu curso de especialização em Educomunicação no Departamento de Comunicações e Artes (CCA) da ECA-USP.

Inicialmente, trataremos de contextualizar a problemática aqui delimitada alinhavando algumas considerações que nos ajudem a entender a violência escolar como um problema de comunicação, ou melhor, de "incomunicação".

Na segunda parte, apresentaremos um breve histórico das ações educomunicativas vinculadas ao poder público, particularmente daquelas que derivaram da parceria com o Núcleo de Comunicação e Educação (NCE) da ECA-USP no período 2001-2014.

Na sequência (terceira parte), trataremos de dois conceitos-chave relativos a práxis educomunicativa como um elemento transformador das relações na escola, constituídos pelo Ecossistema Comunicativo e pela Mediação.

Ao final, concluiremos com algumas considerações que, acreditamos, podem orientar os próximos passos para o questionamento aqui retomado.

\section{A ESCOLA NOS DIAS DE HOJE: TEMPOS DE (IN) COMUNICAÇÃO}

Segundo Martín-Barbero ${ }^{4}$, há uma questão importante na discussão sobre ensino-aprendizagem hoje e que está permeando as instituições de educação: trata-se da visível disparidade das culturas que se chocam dentro da escola 
- de um lado, o modelo de saber instrucional e de outro, o "[...] potencial de saberes diversos, mas entrelaçados, que provêm menos do saber escolar que de sua experiência cultural e vital imersa de corpo inteiro na terceira dimensão digital [...]" .

As condições de existência das escolas vêm se modificando pela aprendizagem contínua, a qual se edifica ao longo de toda uma vida e que não pode mais separar-se do saber comum, "[...] desvalorizando a barreira que ergueu o positivismo entre a universalidade da ciência e a particularidade do saber da experiência”"

Estudar, hoje, é uma experiência bastante complexa, apoiada em referenciais diversos, pois, os sujeitos identificam-se com diferentes espaços, trabalhos, gostos e estilos de vida. A esse conjunto, soma-se ainda o exercício da sensibilidade dos corpos, campo em que a escola costuma pouco participar, "[...] porque ele e suas emoções desestabilizam a autoridade dos professores"

Podemos constatar, assim, que os campos da Comunicação e Educação se tornaram lugares interdiscursivos tensos, como dois universos que parecem "brigar" entre si, o que nos leva a pensar na necessidade de um estreitamento do diálogo entre ambos na instituição escolar.

Vale ressaltar também a presença de uma visão redutora que circunscreve a comunicação educativa apenas à esfera midiática (entendida como o âmbito informal da educação), pois ela está presente em todo o processo pedagógico formal, identificada com os meios tecnológicos empregados. Confrontar essa visão "implica considerar a Comunicação não como um mero instrumento midiático e tecnológico, e sim, antes de tudo, como um componente pedagógico"8.

Além disso, o impacto das mudanças científicas e tecnológicas, intensificadas nas últimas décadas com o surgimento da chamada revolução da sociedade informatizada, estremece os velhos alicerces da escola, evidenciando a necessidade de mudanças. Nesse contexto o desenvolvimento da competência comunicativa dos sujeitos é essencial para uma educação que privilegie o diálogo, a cooperação solidária e valorize as identidades culturais, contrapondo-se a um processo educacional alienante e avassalado pelo mercado, pela competitividade e a tendência à homogeneização cultural.

O cenário aqui descrito não é exatamente novo, mas atinge dimensões hiperbólicas quando nos debruçamos sobre a questão da violência escolar, já que seus efeitos se evidenciam bastante, tanto no plano simbólico - agressões ao espaço "sagrado" da escola - quanto no aspecto objetivo, já que o prejuízo aos indicadores de qualidade e desempenho escolares são concretos e até mensuráveis.

Há uma lógica difícil de ignorar que associa o vandalismo e as agressões verbais e físicas dirigidas a colegas e professores a pelo menos dois tipos de interação desarmônica entre alunos e escola: uma delas seria a frustração de expectativas, entendendo que o lugar que deveria ser de crescimento intelectual e integração social é um ambiente regulado por velhos princípios que não dialogam com os saberes contemporâneos, principalmente com aqueles dos quais os
5 Idem, p. 126.

6 Idem, p. 127

7 Idem, p. 131

8 KAPLÚN, Mario. Processos educativos e canais de Comunicação In: CITELLI, A. O; COSTA, M. C. C. (orgs.). Educomunicação: construindo uma nova área de conhecimento. São Paulo: Paulinas, 2011. 
9 GUIMARÃES, Áurea M. Uma visão alegórica da violência: fragmentos e ruínas. In: BICUDO, Maria A. V.: SILVA Jr., Celestino Alves. Formação do educador e avaliação educacional. Volume 4. São Paulo: Editora Unesp, 1999.

10 SÃO PAULO, Assembleia Legislativa. Lei $\mathrm{n}^{\circ}$. 12.730, de 11/10/2007 (Projeto de lei $n^{\circ}$. 132/2007, do deputado Orlando Morando PSDB), promulgada pelo prefeito José Serra em 12 de outubro de 2007 (data de publicação no D.O.E.S.P.). Disponível em: <http://dobuscadireta.im prensaoficial.com.br/de fault.aspx? DataPublicaca $o=20071012 \&$ Caderno $=D$ OE-I\&NumeroPagina $=1>$. Acesso em: 25 mar. 2015.

11 SÃO PAULO, Prefeitura Municipal, Lei n. 13.941 de 28/12/2004. Disponível em: <www3.prefei tura.sp.gov.br/cadlem/ secretarias/negocios_ju ridicos/cadlem/integra. asp?alt $=29122004 \mathrm{~L} \% 20$ $139410000 \% 20 \% 20$ $\% 20 \% 20 \% 20 \% 20 \% 20$ $\% 20 \% 20 \% 20 \% 20 \% 20$ $\&$ secr $=\&$ depto $=\&$ descr tipo $=\mathrm{LE}>$. Acesso em: 20 mar. 2015. jovens compartilham. Também existe a interação desarmônica física, visível no próprio layout das escolas, caixotes de concreto murados e repletos de grades, lembrando muito as instituições prisionais. Neles, a vigilância repressiva e a imposição da hierarquia de forma heterônoma provocam as reações esperadas: desinteresse, dispersão, evasão.

Outro aspecto que podemos relacionar a essa violência é a ideia do não pertencimento: além de estranho e hostil, o espaço escolar, porquanto público, sendo de todos, parece não ser de ninguém. Ali, sem o bônus do usufruto pleno e nem o ônus dos compromissos e das responsabilidades - ambos inerentes à noção de "propriedade" —, que vínculos podem estabelecer seus "frequentadores" com o locus no qual passam, todos eles, uma parte substancial de seu tempo de vida? E se não se consolidam os vínculos, que mal pode advir da destruição de móveis e objetos que não pertencem a ninguém?

E o que dizer da intervenção do espaço visual com desenhos e pichações, reconhecidas manifestações de expressão comunicativa e busca de apropriação de espaço. É sabido que as manifestações gráfico-visuais da cultura hip hop, como o pixo e o grafitti (além da música rap e da dança break), eram formas de comunicação e demarcação de identidade e território dos grupos marginalizados no contexto urbano da sociedade norte-americana ${ }^{9}$. Em essência, tratamos aqui de tentativas de atribuir sentido e de apropriação do espaço escolar, legitimadas pela ausência do diálogo e pela invisibilidade das manifestações dos sujeitos-alunos.

Logo, ante o empoderamento dos jovens pelas linguagens midiáticas e seu aparente desapego pelo saber formal, despejado a conta-gotas na sala de aula (se comparado ao tsunami digital de informação, representado pela internet), é natural que a escola reaja com tentativas de repressão e de controle de acesso às mídias.

Um bom exemplo de tendência pode ser encontrado na mal-ajambrada Lei n. 12.730 de $11 / 10 / 2007^{10}$ a qual, basicamente, se ocupa de proibir o telefone celular nos estabelecimentos de ensino do estado de São Paulo, um dispositivo de comunicação já incorporado na cultura e no imaginário dos estudantes e que é, inclusive, usado como recurso pedagógico em diversos contextos.

Por outro lado, o fato de uma instância administrativa com as dimensões e a importância da SME-SP ter avançado em direção a uma alternativa tão ousada quanto a Educomunicação (quando a regra seria insistir reprimindo os "transgressores") indica um grau de consciência elevado do poder público no diagnóstico do problema e na busca por soluções fora da ortodoxia burocrática.

Boa parte do êxito pode ser reputada à Lei 13.941 de 28/12/2004 (São Paulo. 2004)", chamada, não por acaso, de "Lei Educom", sancionada em 2005: ela garantiu, em grande medida, a permanência da Educomunicação como um referencial epistemológico dentro das orientações curriculares da SME-SP, além do suporte legal para portarias e decretos regulamentadores que dela derivaram.

Abordaremos, na sequência, o processo histórico que consolidou as práticas educomunicativas na rede pública municipal de São Paulo, amparadas, desde o primeiro momento, na justificativa de sua possível contribuição para a questão da violência escolar. 


\section{PROJETO EDUCOM.RÁDIO E PROGRAMA NAS ONDAS DO RÁDIO: AÇÕES EM FAVOR DA CULTURA DA PAZ}

Já em 2001 a SME-SP publicou um plano de ação retomando a concepção da escola como um espaço democrático e promotor de cidadania, fundada na tríade democratização da gestão da escola; democratização do acesso e garantia da permanência; sob a égide da qualidade social da educação.

No mesmo ano o NCE-ECA-USP foi convidado a formular uma linha de ação para o combate às diversas formas de violência em toda a rede de ensino fundamental da cidade visando lidar com o problema da violência escolar endêmica.

Assim nasceu o Educom.Rádio, um dos projetos específicos em que se desdobrou o Projeto Vida, juntamente com o projeto Escola Aberta "e algumas iniciativas relacionadas às questões de gênero e etno-raciais". O objetivo principal de tais iniciativas era, na perspectiva da "aproximação escola-comunidade", além de "tomar o problema da violência como foco de intervenção"12.

O Projeto Vida entendia a violência como um fenômeno de exclusão social que afetava todas as parcelas da população, e, de maneira mais contundente, os jovens que se encontram na periferia das grandes cidades em situação de vulnerabilidade social.

O conceito de vulnerabilidade social juvenil foi tema de estudos realizados pela Fundação Seade ${ }^{13}$, que formulou um índice para subsidiar políticas na prevenção da violência na cidade de São Paulo. Com base nele, o curso "Educomunicação pelas ondas do rádio" foi concebido para atender professores, alunos e membros das comunidades educativas de escolas da prefeitura de São Paulo. Ali, o trabalho com a linguagem radiofônica - com um equipamento completo para produção e transmissão restrita de rádio - era desenvolvido conjuntamente por professores e alunos em ações educomunicativas solidárias e integradas às práticas curriculares.

Tais ações tinham um duplo objetivo: combater a violência e favorecer uma Cultura da Paz num determinado "Ecossistema Comunicativo" (conceito que abordaremos mais detalhadamente na próxima seção deste artigo): as escolas do ensino fundamental da rede pública municipal.

O que chamamos aqui de Cultura da Paz também merece uma definição à parte:

É um conjunto de atitudes, valores, estilos de vida, sentimentos, baseados no respeito e reverência pela vida e à diversidade, na recusa à violência, na escuta do outro para compreendê-lo, na preservação do planeta, na solidariedade, na busca do equilíbrio das relações entre os seres humanos e desses com todos os seres vivos, no fortalecimento da democracia e dos direitos humanos, em harmonia com a Terra e com a totalidade maior da qual fazemos parte ${ }^{14}$.

Em 2005, o projeto Educom.Rádio, após sua consolidação, passou a se chamar Programa Nas Ondas do Rádio, que hoje atende alunos da educação infantil e do ensino fundamental e médio em projetos de rádio escolar, jornal mural e comunitário, agência de notícias e audiovisual, entre outros suportes midiáticos, sempre apoiados nos pressupostos da Educomunicação.
12 SILVA, Camila C. et al. Educação na capital paulista: um ensaio avaliativo da política municipal (2001-2002). São Paulo: Instituto Pólis, 2004, p. 44.

13 SEADE. Fundação Sistema Estadual de Análise de Dados. Índice Paulista de Vulnerabilidade Social: versão 2010. Disponível em: <www.iprsipvs. seade.gov.br/view/index. php?prodCod=2>. Acesso em: 6 maio 2015

14 INSTITUTO PÓLIS. Cultura viva, políticas públicas e cultura da paz: Cadernos de proposições para o século XXI. Volume 14. São Paulo, Instituto Pólis 2013, p. 205. 
Depois de resgatar o processo histórico de inserção das ações educomunicativas junto à rede municipal em São Paulo, cabe aproximar a discussão do estado de arte dos conceitos educomunicativos que podem responder ao nosso questionamento inicial. Estes serão objeto de nossa próxima seção.

\section{EDUCOMUNICAÇÃO E VIOLÊNCIA ESCOLAR: SUBSÍDIOS PARA UM DEBATE CONTEMPORÂNEO}

As décadas já acumuladas de ação prática e reflexão epistemológica sobre a Educomunicação ainda não nos permitem responder cabalmente as diversas perguntas acumuladas sobre o papel social e a pertinência dela enquanto "novo paradigma educativo".

Essa é a justificativa mais evidente para as pesquisas sobre a natureza e o potencial da abordagem educomunicativa na interface Comunicação/Educação, sendo, inclusive, a demanda que originou o presente artigo.

Entretanto, existem alguns conceitos-chave dentro da Educomunicação, os quais podemos, com relativa certeza, chamar de consolidados. No âmbito de nossa discussão, apontamos como tais a mediação e o ecossistema comunicativo.

A mediação, conceito amplo e flexível, aportado diretamente da Teoria das Mediações de Martín-Barbero ${ }^{15}$, pode ser identificada na ação direta do educomunicador, como um processo de contextualização dialógica entre os vários atores do processo pedagógico e destes com o conjunto de saberes ou as interfaces e repositórios que os comportam - leia-se: os media.

A ação do mediador educomunicativo é, portanto, horizontal, aberta, plural e conciliadora de diversos pontos de vista, se aproximando muito da acepção jurídico-política da "mediação de conflitos".

O papel do educomunicador se distingue, portanto, do de um "ensinante", sem prejuízo da intencionalidade educativa inerente ao âmbito formal da escola. Em nossa visão, longe de buscar uma ruptura com o modelo escolar vigente, tal abordagem agrega uma dimensão integradora e complementadora extremamente necessária na educação contemporânea.

A inclusão dos media e das múltiplas linguagens que neles se aglutinam (textual, audiovisual, digital etc.) buscam estabelecer o diálogo com as novas gerações de estudantes que nascem e crescem sob a influência desta cultura digital.

Por outro lado, a mediação crítica de tais instâncias no meio escolar, tarefa assumida pelo educomunicador, incorpora e faz avançar tanto a leitura crítica da mídia quanto a instrumentalização de suas tecnologias. Tais fenômenos, bastante presentes na escola, se identificam, respectivamente, com o "denuncismo" dos conteúdos midiáticos e com a fetichização dos recursos tecnológicos

15 MARTÍN-BARBERO, J. Dos meios às mediações: comunicação, cultura e hegemonia. Rio de Janeiro: UFRJ, 2003. (pressupondo sua neutralidade ideológica).

Não podemos nos esquecer de que a mediação educomunicativa se apoia, necessariamente, na noção do Ecossistema Educomunicativo, entendendo que: 
Diferentemente dos que, como Martín-Barbero, empregam o conceito para designar a nova atmosfera gerada pela presença das tecnologias às quais cada um de nós e a própria educação estaríamos compulsoriamente conectados, preferimos usar o termo como uma figura de linguagem para nomear um ideal de relações, construído coletivamente em dado espaço, em decorrência de uma decisão estratégica de favorecer o diálogo social, levando em conta, inclusive, as potencialidades dos meios de comunicação e de suas tecnologias ${ }^{16}$.

Assim, a contextualização do espaço escolar como uma teia de relações que almeja o equilíbrio pelo estabelecimento de fluxos multidirecionais e pela ação sinérgica dos sujeitos rumo à construção coletiva e colaborativa dos saberes pode propiciar uma base consistente para um projeto pedagógico que não apenas comporte a Educomunicação, mas que nela se sustente.

Partindo das vivências empíricas, parcialmente sistematizadas (até incipientes, em alguns casos) aqui relatadas, podemos visualizar a construção de um modus facciendi - não necessariamente de uma metodologia no sentido estrito - que justifique e oriente a intervenção educomunicativa em contextos educacionais conflituosos.

O objetivo que almejamos não visa somente a redução de danos, para garantir "condições mínimas" de convivência entre alunos, professores e o restante da comunidade escolar, pois isto seria aceitar como natural a persistência da agressão (diferente do "conflito") como um componente da dinâmica escolar.

Também não reivindicamos para a Educomunicação o papel de "tábua de salvação" da escola e do educador — ambos, instituição e agente da pedagogia - tão criticados e responsabilizados pelo fracasso do sistema educacional.

O que pretendemos, ao final de nossa argumentação, é reiterar que as demandas que mobilizaram a adoção de práticas educomunicativas no contexto da escola pública permanecem válidas e que a avaliação geral de sua efetividade é positiva ${ }^{17}$. Tais afirmações nos levam à forte recomendação para o desenvolvimento de ações de pesquisa e extensão/aplicação direcionando as práticas educomunicativas para a perspectiva de mediação de conflitos a partir das relações comunicativas.

Esta seria, por exemplo, uma habilidade a ser desenvolvida sistematicamente no âmbito dos cursos de formação de educomunicadores, tais como aqueles que se desenvolvem no CCA-ECA-USP e em diversos outros departamentos e centros de formação existentes no país.

\section{CONSIDERAÇÕES FINAIS}

A questão fundamental colocada no início deste artigo versa sobre a efetividade da Educomunicação, expressa em suas práticas e ações, na redução da violência escolar.

Tal enunciado já denota que consideramos como fator decisivo, nesta forma específica de violência, o conjunto de problemas de comunicação na escola.

16 SOARES, Ismar de O. Educomunicação: o conceito, o profissional, a aplicação. São Paulo: Paulinas, 2011, p. 44. 17 SILVA et al, op. cit. 
Também tratamos das ações educomunicativas inseridas como política pública na educação formal, processo em franca expansão e consolidação e do qual pudemos apreciar alguns aspectos históricos no exemplo paulistano.

Partindo desse apoio, nossa linha de argumentação estabelece uma abordagem em três instâncias: a da fundamentação teórica, a do planejamento das ações e da investigação empírica, preferencialmente, com o uso de instrumentos quantitativos.

É forçoso entender que o âmbito reduzido deste artigo não nos permite avançar além do plano da justificativa para retomar esta questão num trabalho (acadêmico ou não) de muito maior escopo, além de esboçar alguns aportes para a instância teórica, o que, aliás, buscamos fazer na seção anterior.

Resta considerar que, além de um aprofundamento aplicado do conceito de mediação educomunicativa aliado à noção mais precisa do que seja o Ecossistema Comunicativo (o que responderia pela demanda da segunda instância), se faz necessário, em momento posterior, acompanhar, registrar e avaliar a efetividade de tais ações na redução da violência.

Esta última talvez seja a tarefa mais dispendiosa no afã de responder nossa questão fulcral e, de longe, a mais controversa, já que depende da análise de inúmeras variáveis cujo impacto tende a se modificar do contexto de uma escola para o de outra.

Do ponto de vista metodológico, subentende-se a necessidade de uma amostragem significativa, a qual representa, em termos de escola pública, o envolvimento de dezenas de milhares de sujeitos.

Assim, podemos concluir que, num alcance restrito, o desenvolvimento recomendado para a nossa discussão levaria a um incremento do referencial teórico da Educomunicação, fechando o ciclo "Investigação empírica à Reflexão crítica à Aplicação prática dos conceitos”, o qual pudemos mapear no trajeto histórico de suas práticas.

Finalizando, as possibilidades aqui discutidas nos permitem ambicionar um alcance ainda mais amplo para tais ações: se a Educomunicação pode apoiar práticas efetivas que reduzam a violência sem lançar mão de condutas repressivas (afinal, não se trata de "combatê-la"), nada impede, em tese, que ela seja adotada em outras áreas de conhecimento compatíveis com sua natureza transversal/transdisciplinar. Isso já vem ocorrendo, diga-se de passagem, em relação à área Socioambiental, de Saúde e até da formação profissional ("mundo do trabalho").

O desafio está lançado.

\section{REFERÊNCIAS}

CONSANI, M. A.; LEÃO M. I. de A. Nas ondas do rádio: a experiência educomunicativa e midiática dos professores de São Paulo. Texto publicado nos Anais do I Congreso de Educacion Mediatica y Competencia Digital. Disponível 
em: $\quad$ http://educacionmediatica.es/comunicaciones/Eje\%203/Marciel\%20 A.\%20Consani\%20e\%20Izabel\%20Le\%C3\%A3o.pdf>. Acesso em: 25 mar. 2015. GUIMARÃES, Áurea M. Uma visão alegórica da violência: fragmentos e ruínas. In: BICUDO, Maria A. V.; SILVA Jr., Celestino Alves. Formação do educador e avaliação educacional. Volume 4. São Paulo: Editora Unesp, 1999. INSTITUTO PÓLIS. Cultura viva, políticas públicas e cultura da paz: Cadernos de proposições para o século XXI. Volume 14. São Paulo, Instituto Pólis, 2013.

JIMENEZ, Márcia Coutinho R. Vídeo Institucional Projeto Educom.Rádio. 2011, cor, 18m19s, formato digital. Disponível em: <www.youtube.com/ watch?v=FDEVvZY164U>. Acesso em: 25 mar. 2015.

KAPLÚN, Mario. Processos educativos e canais de comunicação In: CITELLI, A. O; COSTA, M. C. C. (orgs.). Educomunicação: construindo uma nova área de conhecimento. São Paulo: Paulinas, 2011.

MACCAGNINI, Maria Carolina A. Educomunicação na escola: a violência urbana na cidade de São Paulo e o caso da EMEF Professora Marili Dias. Monografia do curso de Especialização em Educomunicação apresentada ao CCA-ECA-USP, São Paulo, 2015.

MARTÍN-BARBERO, J. A comunicação na educação. São Paulo: Contexto, 2014. Dos meios às mediações: comunicação, cultura e hegemonia. Rio de Janeiro: UFRJ, 2003.

SEADE. Fundação Sistema Estadual de Análise de Dados. Índice Paulista de Vulnerabilidade Social: versão 2010. Disponível em: <www.iprsipvs.seade.gov. $\mathrm{br} /$ view/index.php?prodCod=2>. Acesso em: 6 maio 2015.

SILVA, Camila C. et al. Educação na capital paulista: um ensaio avaliativo da política municipal (2001-2002). São Paulo: Instituto Pólis, 2004.

SOARES, Ismar de O. Educomunicação: o conceito, o profissional, a aplicação. São Paulo: Paulinas, 2011.

SÃO PAULO, Assembleia Legislativa. Lei ${ }^{\circ}$ 12.730, de 11/10/2007 (Projeto de lei $\mathrm{n}^{\circ}$ 132/2007, do deputado Orlando Morando - PSDB), promulgada pelo prefeito José Serra em 12 de outubro de 2007 (data de publicação no D.O.E.S.P.). Disponível em: <http://dobuscadireta.imprensaoficial. com.br/default.aspx? DataPublicaca $0=20071012 \&$ Caderno=DOEI\&NumeroPagina=1>. Acesso em: 25 mar. 2015.

SÃO PAULO, Prefeitura Municipal, Lei 13.941 de 28/12/2004. Disponível em: $<$ www3.prefeitura.sp.gov.br/cadlem/secretarias/negocios_juridicos/cadlem/ integra.asp?alt=29122004L $\% 20139410000 \% 20 \% 20 \% 20 \% 20 \% 20 \% 20 \% 20 \% 20$ $\% 20 \% 20 \% 20 \% 20 \& s e c r=\& d e p t o=\& d e s c r \_t i p o=L E I>$. Acesso em: 20 mar. 2015. 